\title{
Experiência no selo editorial Malha Fina Cartonera
}

\author{
Experiencia en el sello editorial Malla Fina Cartonera
}

\author{
LARISSA PAVONI RODRIGUES
}

\begin{abstract}
RESUMO
Este trabalho apresentará alguns aspectos da minha experiência como monitora no projeto "Selo Editorial Malha Fina Cartonera", pertencente ao Programa Unificado de Bolsas (Cultura e Extensão), em vigência durante o período entre setembro de 2016 e agosto de 2017. O projeto apresenta-se como espaço difusor de literatura e de publicação independente na Universidade de São Paulo, e pretende estimular e dar visibilidade a autores inéditos no ambiente acadêmico e fora dele. Igualmente, visa a formação dos alunos de graduação da área do Espanhol e demais áreas no âmbito editorial. Ministramos oficinas de produção de livros, participamos de feiras, produzimos um blog com conteúdos relativos ao universo cartonero, resenhas literárias, entrevistas, reportagens, publicação de textos literários, etc. Os livros cartoneros são confeccionados de maneira simples e com baixo custo: capas feitas à mão, individualmente, com papelão reciclado e folhas costuradas. Cada edição é uma peça única e sustentável na mão do leitor.
\end{abstract}

PALAVRAS-CHAVE: projeto de extensão; publicação independente; cartonera.

\section{RESUMEN}

Este trabajo presentará algunos aspectos de mi experiencia como monitora en el proyecto "Selo Editorial Malha Fina Cartonera", perteneciente al Programa Unificado de Bolsas (Cultura e Extensão), en vigencia durante el periodo entre septiembre de 2016 y agosto de 2017. El proyecto se presenta como un espacio difusor de literatura y de publicación independiente en la Universidade de São Paulo, y pretende estimular y dar visibilidad a autores inéditos en el ambiente académico y también fuera de él. Igualmente, objetiva la formación de los alumnos de graduación del área de Español y demás áreas en el ámbito editorial. Ministramos talleres de producción de libros, participamos de ferias, producimos un blog con contenidos relativos al universo cartonero, reseñas literarias, entrevistas, reportajes, publicación de textos literarios, etc. Los libros cartoneros se confeccionan de manera simple y con bajo costo: tapas hechas a mano, individualmente, con cartón reciclado y hojas cosidas. Cada edición es una pieza única y sostenible en la mano del lector.

PALABRAS CLAVE: proyecto de extensión; publicación independiente; cartonera.

Este trabalho é baseado no Relatório Final ${ }^{1}$ do projeto "Selo Editorial Malha Fina Cartonera", apresentado ao Programa Unificado de Bolsas, no qual relato as ações e a experiência como monitora durante setembro de 2016 até agosto de 2017. Esse projeto nasceu no segundo semestre de 2015 na área de Espanhol do Departamento de Letras Modernas da Universidade de São Paulo, com o apoio do Programa Unificado de Bolsas (Cultura e Extensão), coordenado pela professora Idalia Morejón Arnaiz.

O termo Cartonera vem de cartón em espanhol, que significa papelão. A história das editoras cartoneras começa na Argentina em 2003, em meio a uma grande crise econômica e política no país, com a fundação da Eloísa Cartonera, por iniciativa do escritor Washington

\footnotetext{
${ }^{1}$ O Relatório Final foi baseado em dois textos escritos pelos monitores do projeto e publicados no blog, a primeira em dezembro de 2016 e a segunda em junho de 2017, referentes à retrospectiva do projeto nos semestres. Disponível em: <https://malhafinacartonera.wordpress.com/>. Acesso em: 13 de outubro de 2017.
} 
Cucurto e do artista plástico Javier Barilaro. Atualmente, o movimento cartonero está espalhado por países da América Latina, Europa, África e Ásia.

Os livros cartoneros são produzidos artesanalmente com papelão proveniente de caixas descartáveis, coletadas nas ruas ou comprado diretamente com os catadores de papelão por um valor superior ao oferecido pelas empresas de reciclagem, que gira em torno de 20 centavos o quilo. O papelão é reutilizado como capa e contracapa do livro, após ser cortado, pintado e costurado à mão através do trabalho de criação em equipe.

O principal objetivo do movimento cartonero é publicar livros de qualidade literária a baixo custo, promovendo a difusão e a circulação da literatura com a participação de diversos setores da sociedade no processo de produção: catadores de papelão, estudantes, escritores, artistas plásticos e tradutores.

Trabalhar com o papelão é tão fácil e rápido que queremos incentivar mais autores, escolas, cursos e faculdades a construírem projetos autônomos, difusores da ideia de um selo editorial que incentive a vida literária onde quer que esteja.

Uma de nossas principais ações é a manutenção, desde 2015, de um blog no qual os bolsistas e colaboradores publicam textos semanalmente, sempre às quartas-feiras. Atualmente, o blog é subdividido nas seções Caindo na Malha Fina (de resenhas), Modus Operandi (de tradução), Na Batida Cartonera (de reportagens), Transversal (de entrevistas) e Sangria, a mais nova seção voltada à publicação de novos autores.

Sobre as publicações, lançamos os primeiros livros dia 15 de abril de 2016, no prédio da Maria Antonia. São quatro títulos de autores ligados à nossa faculdade: 22 poemas, de Fabiano Calixto, Os olhos dos pobres de Julián Fuks, Diálogos e Incorporações de Juliano Garcia Pessanha e O pretexto para todos os meus vícios de Heitor Ferraz. Estes livros foram feitos em parceria com outras editoras cartoneras: a Mariposa Cartonera, de Recife, a Yiyi Jambo, de Ponta Porã e a La Sofia Cartonera, de Córdoba, na Argentina.

No mesmo dia desse lançamento, anunciamos os ganhadores da Primeira Convocatória para Publicação de Narrativa e Poesia da Malha Fina. A convocatória buscou selecionar estudantes da graduação e pós-graduação da Faculdade de Filosofia, Letras e Ciências Humanas da Universidade de São Paulo, que nunca tinham publicado, e os vencedores foram: Crisântemo é um nome bom, do Mauro Augusto de Sousa (Filosofia) e O coração em si do Elvio Fernandes Gonçalves Junior (Letras - Linguística), que tiveram seus livros publicados no início de 2017.

Ainda em abril de 2016, a Malha Fina publicou a antologia Poesia Língua Franca, composta por dez poetas hispano-americanos traduzidos ao português, cinco mulheres e cinco homens. O lançamento aconteceu no Centro Cultural B_arco, em Pinheiros, em um sarau no qual os tradutores e colaboradores da Malha Fina Cartonera leram os poemas da antologia. Nossos livros, a partir de então, receberam um trabalho gráfico da designer Iara Pierro de Camargo, colaboradora do projeto. 
Publicamos também as obras: 2 Ensaios, do cubano Antonio José Ponte, traduzido pela Clarisse Lyra, aluna da pós, e A Escrita Riscada do porto-riquenho Eduardo Lalo, traduzido pela Chayenne Mubarack, colaboradora da Malha Fina. Tratam-se de obras inéditas no campo editorial brasileiro e apontam um dos objetivos da Malha Fina que é expandir no Brasil o acesso e o conhecimento sobre as literaturas do Caribe.

Durante a Jornada do Programa de Pós-graduação em Língua Espanhola e Literaturas Espanhola e Hispano-Americana, em agosto de 2016, lançamos a Antologia bilíngue Diáspora(s), nosso mais novo livro, juntamente com uma oficina que ministramos sobre como fazer um livro cartonero.

Também fizemos oficinas em escolas públicas de São Paulo, a primeira foi em outubro de 2016, na Escola Municipal General Euclydes de Oliveira Figueiredo, com jovens de 11 a 15 anos, como parte de um projeto cartonero que está sendo implementado na escola pela professora Silvia Martins. Os livros confeccionados foram escritos pelos próprios alunos, trabalhados em conjunto com as professoras de português. Entre eles, uma coletânea intitulada Contos de Terror, outra de poesia e o livro Simão está dormindo, do escritor Paulo Nunes.

Entre os dias 22 e 27 de novembro de 2016, a Malha Fina participou de dois grandes eventos: a Festa do livro da USP, e a LER - Salão Carioca do Livro, em parceria com a Mariposa Cartonera, de Recife. O Salão Carioca do Livro foi a primeira viagem em equipe da Malha Fina, que foi representada pelas coordenadoras Idalia Morejón e Tatiana Faria, e as monitoras Larissa Pavoni e Mariana Costa Mendes. Durante os quatro dias, a programação do evento contou com a presença de vários escritores, escritoras e artistas reconhecidos. Além de vender os livros cartoneros, tivemos a oportunidade de estar ainda mais em contato com o público em duas oficinas oferecidas no espaço Oficina Literária, em que explicamos o nosso projeto para cerca de 50 pessoas, entre crianças e adultos, e demonstramos o fazer do livro cartonero.

Também em novembro de 2016, a equipe da Malha Fina ministrou mais duas oficinas: $u$ ma como parte da IV Jornada Pedagógica da Diretoria Regional de Educação do Butantã e outra na Escola Municipal Jocymara Jorge, em Guarulhos. Na Jornada do Butantã participaram professores da rede pública de ensino, debatendo não só sobre a natureza das cartoneras e os processos de confecção dos livros, mas também sobre o tema "Currículo Emancipatório em Movimento: Reencantamento do Mundo e da Educação” e sobre as possibilidades de disseminar esse projeto nas escolas, contribuindo para a produção literária e artística dos alunos.

Já no início de 2017, participamos da Desvairada - Feira de livros de Poesia de São Paulo, no espaço Aldeia 445. O evento organizado por Marília Garcia, Fabiano Calixto, Leonardo Gandolfi e Tiago Marchesano contou com uma diversificada programação que abrangia mesas de debate, leituras de poemas, oficinas, concurso de vídeo-poemas, performances e atividades para crianças. Nós, da Malha Fina, além de comercializarmos os livros, ministramos uma 
oficina cartonera, que abordou desde a edição de livros artesanais até a construção de um catálogo. Tatiana Faria, os monitores Larissa Pavoni e Pacelli Dias, e a designer gráfica Iara falaram sobre as várias etapas do fazer cartonero. Ainda na Desvairada, com o objetivo de colaborar com a difusão do trabalho das editoras independentes, entrevistamos e gravamos uma série de vídeos com os responsáveis por todas as editoras presentes, que podem ser acessados no nosso canal no Youtube.

Em 2017, mais uma vez, o blog mostrou-se uma ferramenta importante de divulgação, não só dos eventos organizados ou para os quais a Malha Fina foi convidada, mas também de questões relativas ao universo das editoras independentes e cartoneras. Começamos as publicações com uma entrevista com a precursora do movimento cartonero no Brasil: Lúcia Rosa, do Coletivo Dulcineia Catadora, que completou 10 anos de atividade no centro de São Paulo e cujo catálogo conta com 114 títulos publicados, além de um sólido trabalho de divulgação através de oficinas.

Já no "Passo a passo cartonero da Malha Fina", detalhamos todo o nosso processo de produção de livros, com a descrição dos modos de fazer e uma lista dos materiais necessários. Os vídeos demonstrativos foram produzidos pela colaboradora Júlia Izumino e pela Larissa Pavoni, e a edição ficou por conta de Mariana Costa Mendes. Esperamos que o Passo a Passo seja um convite para impulsionar a prática cartonera. Por fim, na última semana de maio lançamos "Sangria", uma nova seção do blog que tem como objetivo a divulgação de novos autores.

O nome "Malha Fina" pode apresentar alguns significados. Um deles, e o de que mais gostamos, é que malha fina vem da lâmina que pretende desnudar outras faces, outros meios. Abrindo caminho ao novo, à formação e publicação de novos estudantes, novas traduções, revisões, projetos gráficos, etc. A Malha Fina pretende estimular e dar visibilidade a autores inéditos em nosso meio e fora do ambiente acadêmico também: materializa-se da necessidade de mais vida literária no nosso cotidiano, mais projetos formadores e transformadores. 